\title{
Nacional, democrático e social: o desenvolvimentismo chileno durante os governos radicais
}

\author{
National, democratic and social: Chilean \\ developmentalism during radical governments
}

JULIA VEIGA VIEIRA MANCIO BANDEIRA* PEDRO PERFEITO DA SILVA**

\begin{abstract}
RESUMO: A primeira experiência desenvolvimentista chilena ocorreu durante os quatorze anos (1938-1952) de governos democráticos do Partido Radical. Tal partido, apesar de ser formado pelas classes médias, tinha a questão social e a diminuição da dependência externa como preocupações centrais. Assim, o objetivo do presente artigo é entender as especificidades dos governos desenvolvimentistas e radicais no Chile, partindo do argumento que eles perseguiram, concomitantemente, a construção de um desenvolvimentismo nacional, democrático e social. Para tanto, será explorado o conceito de desenvolvimentismo em si, para então analisar política econômica do período.

PALAVRAS-CHAVE: Desenvolvimentismo; Chile; partido radical.
\end{abstract}

ABSTRACT: The first Chilean developmental experience occurred during the fourteen years (1938-1952) of democratic governments of the Radical Party. This party, despite being composed by the middle classes, had the social question and the reduction of external dependence as central concerns. Thus, the aim of this article is to understand the specificities of Developmental and Radical governments in Chile, starting from the argument that they pursued, simultaneously, the construction of a national, democratic and social development. To do so, the concept of developmentalism itself will be explored to analyze the economic policy of the period.

KEYWORDS: Developmentalism; Chile; radical party.

JEL Classification: N16; O10; O20.

\footnotetext{
* Universidade Federal do Rio Grande do Sul - UFRGS, Porto Alegre/RS, Brasil. E-mail juveigas@gmail. com. Orcid: https://orcid.org/0000-0002-6018-9971.

** Universidade Centro-Europeia - CEU, Viena, Áustria. E-mail pperfeitodasilva@gmail.com. Orcid: http://orcid.org/0000-0002-2469-0996. Submetido: 27/Maio/2019; Aprovado: 17/Junho/2020.
} 


\section{INTRODUÇÃO}

Ao contrário da experiência asiática e, por vezes, da latino-americana, o desenvolvimentismo chileno deu-se dentro dos marcos democráticos. Os primeiros governos desenvolvimentistas no Chile, apesar de decorrerem de alianças de amplo espectro ideológico, eram encabeçados pelo Partido Radical (PR), o qual tinha a questão social e a diminuição da dependência externa como preocupações centrais. A manutenção da democracia engendrou um desenvolvimentismo particular, na medida em que estes governos tiveram que lidar com diversos atores fortes e independentes entre si para formular e implementar suas políticas.

Dessa maneira, o objetivo do presente artigo é compreender as especificidades dos governos radicais no Chile, entre 1938 e 1952. Parte-se do argumento principal de que tal experiência foi excepcional, pois perseguiu, concomitantemente, a construção de um desenvolvimentismo nacional, democrático e social.

A caracterização de tais governos como desenvolvimentistas parte de Fonseca (2014), de modo que será analisada apenas sua feição. Para isso, inicialmente, será explorado o conceito de desenvolvimentismo. Depois, traçar-se-á um quadro geral sobre o contexto que antecedeu os governos radicais, para, então, passar ao detalhamento das características do desenvolvimentismo do período.

\section{DESENVOLVIMENTISMO: CONCEITO, INTENCIONALIDADE E SUBTIPOS}

Dado que o principal objetivo deste artigo é avaliar o caráter desenvolvimentista dos governos radicais no Chile, a tarefa inicial é apresentar o conceito de desenvolvimentismo. Nesse sentido, Fonseca (2014) realiza um esforço de definição a partir do mapeamento dos diversos autores que discutem o tema para, após isso, contrapor o conceito construído com a experiência histórica de uma série de governos latino-americanos. Vale dizer também que aqui, como em Fonseca (2014), o desenvolvimentismo será tratado como um fenômeno do mundo material, representado por diversas políticas econômicas, articuladas em torno de um núcleo comum.

Segundo o autor, o conceito de desenvolvimentismo baseia-se em três atributos: i) a existência de um projeto deliberado ou estratégia de superação do "atraso", tendo como objeto a nação e seu futuro; ii) a intervenção consciente e deliberada do Estado, utilizando políticas econômicas instrumentais e/ou institucionais para alcançar os fins estabelecidos pelo projeto; e iii) a industrialização, enquanto caminho para o desenvolvimento da economia nacional. Somente será caracterizado como desenvolvimentista o governo que apresentar concomitantemente todos esses atributos.

A observação prática dessas características na experiência histórica pressupõe a intencionalidade na ação governamental. A leitura de Fonseca $(2003,2014)$ permite a separação teórica das duas dimensões de uma política econômica desenvolvimentista: i) a formulação de um projeto político, econômico e social que atenda 
aos três atributos do núcleo comum, e que se desdobre em um conjunto de medidas e instituições postas em prática; e ii) a obtenção de resultados em pontos fundamentais como produção industrial, formação bruta de capital, desenvolvimento de setores estratégicos em território nacional, entre outros. A caracterização de um governo enquanto desenvolvimentista passa, quase que exclusivamente, pela primeira dimensão, de modo que não basta o bom desempenho na segunda, sem que se observe intenção prévia na orientação da intervenção estatal. Nesse sentido, uma política econômica desenvolvimentista "não é errática nem apenas reativa aos ciclos ou às flutuações inerentes à conjuntura, mas formulada em consonância a uma pretensão de interferência em seu curso, em busca de uma trajetória previamente definida" (Fonseca, Cunha, Bichara, 2013, p. 412).

Após a definição do conceito de desenvolvimentismo, há que se tratar do lugar das políticas instrumentais nessa discussão. Segundo Fonseca (2014), a política econômica abrange três dimensões: i) políticas-meio ou instrumentais - como a cambial, a fiscal e a monetária - voltadas à estabilidade macroeconômica; ii) as políticas-fins - como a industrial - que se concentram em áreas específicas; e iii) as políticas institucionais, que afetam as regras do jogo por meio de mudanças legais e regulatórias e de criação de órgãos públicos e empresas estatais.

Ao analisar o caso brasileiro da Era Vargas (1930-1945), Fonseca (2003) concentra a sustentação da hipótese da intencionalidade nas duas últimas dimensões, contrapondo-se à teoria dos choques de adversos de Celso Furtado (1977), para qual o avanço do setor industrial brasileiro na década de 1930 tratou-se de um subproduto benéfico de políticas instrumentais voltadas à defesa do setor exportador (cafeeiro) e à reposição do equilíbrio externo e orçamentário. Para o primeiro autor, "as políticas-meio às vezes não permitem que se detecte intencionalidade" (Fonseca, 2014, p. 17).

Dessa maneira, no exemplo brasileiro, a intencionalidade decorreria de uma série de políticas-fins e institucionais como: a reforma tributária de 1934, a facilitação da importação de bens de capital junto aos Estados Unidos em 1935, a criação da Carteira de Crédito Agrícola e Industrial do Banco do Brasil em 1937, a criação do Conselho Nacional do Petróleo, da Companhia Siderúrgica Nacional e da Companhia Vale do Rio Doce, diversas mudanças nos direitos de propriedade (Código de Minas e Código de Águas), o fortalecimento da burocracia estatal (via criação do Departamento Administrativo do Serviço Público), a legislação trabalhista, a reforma educacional, entre outras medidas.

Não obstante, a execução das políticas instrumentais também pode se dar em um sentido coerente com a estratégia desenvolvimentista. Por exemplo, Laan, Cunha e Fonseca (2012) analisam a política cambial ao longo da Era Vargas e concluem que a implementação de um conjunto de reformas institucionais, tais como o regime cambial baseado em taxas múltiplas, serviu ao propósito industrializante, pois permitiu o direcionamento da maior parte das receitas em moeda estrangeira advindas das exportações para o pagamento de importações de bens de capital estratégicos para o desenvolvimento industrial doméstico.

A partir do artigo em questão, depreende-se que a identificação de um sentido 
desenvolvimentista em políticas-meio está associada a um conjunto de mudanças institucionais que a subordinem a objetivos industrializantes, potencializando políticas-fins e institucionais. Ainda assim, a experiência histórica não exclui a possibilidade de um governo desenvolvimentista conciliar políticas instrumentais restritivas, encarando o equilíbrio macroeconômico de curto prazo como condição para a sustentabilidade de uma estratégia de desenvolvimento de médio e longo prazo.

Há ainda outros atributos que não compõem o núcleo duro do conceito, mas que aparecem com frequência na obra de diversos autores. Tendo em vista a experiência chilena, destacam-se os seguintes atributos: bancos de desenvolvimento (Amsden, 1991), burocracia econômica de elite encabeçada por um organismo institucional piloto (Wade, 1999), canais institucionalizados para negociação de metas e políticas entre governo e empresários industriais (Evans, 2004), dentre outros.

Além dos atributos citados acima, Fonseca (2014) identifica a possibilidade de subtipos de desenvolvimentismo, que atendem aos três atributos do conceito clássico, porém apresentam características específicas. No que tange aos objetivos do presente estudo, vale a pena destacar a existência de três antinomias, as quais opõem dois estilos de desenvolvimento tais como: i) nacional versus dependente-associado; ii) autoritário versus democrático; iii) baseado em um padrão de crescimento puxado pelos lucros versus lastreado em um padrão de crescimento puxado pelos lucros.

A primeira antinomia remonta aos trabalhos de Cardoso e Faletto (1970) e Cardoso (1971), os quais caracterizam governos como Vargas e Perón como exemplos de nacional-desenvolvimentismo, bem como o governo Frondizi como um caso de desenvolvimentismo dependente-associado. No primeiro subtipo, o Estado seria o ator fundamental, com capacidade de captar a poupança forçada em torno de uma estratégia voltada à produção de bens de consumo para os trabalhadores, liderada pelo capital privado nacional, com o objetivo de alcançar a produção de bens intermediários e de capital. Em termos políticos, isso passaria por uma coalizão assentada em segmentos médios (a burocracia, inclusive), empresários nacionais e trabalhadores urbanos. Já no segundo subtipo, o capital estrangeiro seria o principal ator, liderando, em associação com o Estado e o capital privado nacional, uma estratégia de industrialização restritiva, centrada na indústria pesada e de bens de consumo duráveis. Politicamente, a demanda majoritariamente originada em camadas de renda mais elevada implicaria uma influência menor dos trabalhadores e suas organizações.

Passando à segunda antinomia, Herrlein Junior (2014) investiga as características de um Estado desenvolvimentista construído a partir da democracia. De acordo com o autor, nesse contexto, um regime político baseado na democracia e no pluralismo poderia viabilizar, junto a outros elementos tais como a democracia deliberativa, o desenvolvimento endógeno de Furtado (1984), a expansão das capacidades humanas (Sen, 1999) e a democratização dos mercados (Unger, 2008). Esse arranjo institucional contrasta com a experiência desenvolvimentista do Leste Asiático. Sobre esta, Wade (1999) destaca o virtual monopólio do poder político 
por parte de algum partido ou instituição política durante largo período, bem como o caráter autoritário dos regimes políticos existentes na região, baseados na exclusão política dos segmentos populares.

Há ainda a antinomia relacionada ao padrão de crescimento associado à política econômica desenvolvimentista. Esse debate é apresentado de forma sistemática em Ferrari Filho e Paula (2015) e Ferrari Filho e Fonseca (2015), expondo estilos de desenvolvimento assentados em um padrão (ou regime) de crescimento liderado pelos lucros (profit-led growth) ou pelos salários ${ }^{1}$ (wage-led growth). Segundo Bhaduri e Marglin (1990), o primeiro caracteriza-se pelo fato de que uma maior participação dos lucros na renda resulta em um aumento no crescimento econômico, enquanto no segundo tal objetivo é atingido a partir de uma participação mais elevada dos salários. Há ainda o chamado export-led growth ${ }^{2}$, que seria um tipo de regime profit-led growth, dado que contém os salários e a demanda doméstica, incentivando as exportações por meio das políticas cambial e industrial (Hein, 2013).

Tendo em vista a explicação do sucesso de uma estratégia nacional de desenvolvimento, Ferrari Filho e Fonseca (2015) sublinham que um padrão de crescimento apenas se configura e é bem-sucedido se a expansão dos salários ou das exportações (variáveis desencadeadoras) for capaz de gerar expectativas positivas ante os lucros, engendrando um maior nível de investimento. Nesse sentido, se a constituição de um padrão de crescimento é fruto de uma política econômica deliberada, ao mesmo tempo, tal decisão é condicionada por diversas variáveis como contexto político, restrições externas e padrão tecnológico vigente.

Além disso, os autores resgatam Keynes (1996) ao destacar que as decisões privadas de investimento dependem de expectativas formadas em bases frágeis a respeito de fatores como demanda futura, grau de confiança, taxa de juros, convenções, dentre outros. Dessa maneira, a ausência de uma relação virtuosa do regime wage-led growth com o investimento privado pode levar ao fenômeno do profit-squeeze, no qual a compressão da margem de lucro prejudica a trajetória de acumulação de capital.

Por fim, há ainda duas dificuldades enfrentadas pelo padrão de crescimento liderado pelos salários. Em primeiro lugar, o pleno emprego, que costuma ser um dos objetivos do regime wage-led growth, costuma não ser bem recebido pelos ca-

\footnotetext{
${ }^{1}$ De acordo com Carneiro (2012), Bastos (2012) e Rossi (2015), uma estratégia de desenvolvimento assentada em um padrão wage-led growth se caracteriza pela subordinação às metas do desenvolvimento social, pela ampliação do consumo de massas, pela centralidade do mercado interno, pela redistribuição de renda como fator dinâmico, pelo crescimento dos salários acima da produtividade (em um primeiro momento) e pela ampliação do crédito.

${ }^{2}$ Bresser-Pereira (2011, 2012), Bresser-Pereira e Gala (2010) e Oreiro e Paula $(2007,2012)$ chamam a atenção para o fato de que a combinação entre crescimento salarial acima da produtividade e taxa de câmbio sobrevalorizado levaria a um contexto de taxa de lucro insatisfatória, prejudicando o investimento privado e a expansão do estoque de capital (fenômeno do profit-squeeze), sendo necessário focar, então, em um crescimento baseado nas exportações.
} 
pitalistas, ainda mais quando se converte em uma política de longa duração e oriunda de intervenção estatal tanto na produção direta quanto na regulação do mercado de trabalho (Kalecki, 1987). Em segundo lugar, em um regime político democrático, a dupla ordenação dos recursos - fruto das decisões privadas dos proprietários e das escolhas sociais impostas pelo Estado - aprofunda a tensão entre Estado e mercado, podendo instabilizar a formação das expectativas dos capitalistas, afetando negativamente o investimento privado (Przeworski, 1989).

\section{O PANORAMA CHILENO PRÉ-DESENVOLVIMENTISMO}

Os anos entre 1925 e 1973 foram, para a história chilena, de profundas transformações. O período, incrustado entre a dissolução do Estado oligárquico e a queda da democracia, presenciou a transição do parlamentarismo ao presidencialismo, o declínio dos partidos tradicionais, a ascensão dos partidos de esquerda, a substituição da exclusão política pela expansão dos direitos políticos e sociais, o início da industrialização e a modernização do Estado chileno. Portanto, para entendermos o modelo de desenvolvimentismo que se formou nos governos radicais é necessário olhar, previamente, para o contexto que o antecedeu.

O sistema parlamentar instituído no Chile em 1891, e que perdurou até 1925, é consequência direta da guerra civil travada no mesmo ano. Os trinta e quatro anos da República Parlamentarista foram caracterizados: i) pela supremacia do Legislativo, e, portanto, dos interesses da oligarquia; e ii) pela economia à mercê das expansões e crises da indústria salitreira, visto que o período está intimamente relacionado com o ciclo do salitre (1880-1930). Nesse sentido, como pontua Meller (1996), a exportação do salitre era a principal fonte de recursos do país, representando em torno de $30 \%$ do PIB e $70 \%$ das exportações totais. A exploração do minério, contudo, estava, predominantemente, em mãos estrangeiras, sendo a receita incorporada pelo Estado chileno oriunda apenas da tributação da exportação, de modo que a cada cem pesos de nitrato produzido, menos de cinquenta centavos permaneciam no país (CRUZ, 1973).

Nos termos de Cardoso e Faletto (1970), tal característica configura uma economia de enclave, na qual o capital de investimento do setor exportador origina-se no exterior e é incorporado aos processos produtivos locais através do pagamento de salários e taxas. Devido a isso, a exploração do salitre teve baixo impacto sobre o desenvolvimento do sistema produtivo local (MELLER, 1996).

A fabricação de nitratos sintéticos na Alemanha e nos Estados Unidos após a Primeira Guerra Mundial levou ao declínio do salitre, pouco competitivo ante os baixos preços dos produtos sintéticos. Nesta conjuntura, a Crise de 1929 conferiu o golpe final à hegemonia do minério, fazendo sua exportação cair $95 \%$ (Arrizabalo, 1995). A diminuição do peso do salitre foi compensada pela crescente exportação de cobre. Não obstante, tal exploração também estava, majoritariamente, nas mãos de empresas estrangeiras, as quais pagavam módicos impostos, deixando no país apenas uma pequena parte do valor produzido (Monteón, 1982). Meller (1990) 
pontua que a substituição de um minério para outro não evitou, então, que o país fosse o mais atingido pela Crise de 1929 na América Latina. Assim, entre 1929 e 1932, o PIB caiu $38,3 \%$ e o PIB per capita $60 \%$; já o nível das exportações e das importações declinou $78 \%$ e $83 \%$, respectivamente.

Apesar da riqueza perdida pelo enclave, é inegável que a exportação de minérios dinamizou, no início do século XX, a estrutura social do país ao estimular a urbanização e uma incipiente industrialização (Palma, 1984). Tais processos ocorreram, contudo, de forma desordenada, gerando uma relevante classe trabalhadora que vivia e trabalhava em péssimas condições. Esse quadro alimentou uma crescente organização e mobilização sindicais, fazendo com que a tensão social permeasse todo o período da República Parlamentarista (Morris, 2000).

Vial (1981) aponta que embora o surgimento da classe trabalhadora como um ator político seja o fato de maior importância histórica no país na virada do século, o regime oligárquico permaneceu impermeável a ela. Isso não só contribuiu com a expansão da mobilização, fazendo com que o Chile conformasse um movimento sindical forte e organizado pelo menos uma década antes de seus vizinhos ${ }^{3}$ (Grez, 2000), como também fomentou uma viragem ideológica nestes movimentos. Assim, se inicialmente eles não transcendiam o debate salarial, a partir da década de 1920 passaram a adotar uma orientação socialista, vinculando-se, principalmente, ao Partido Operário Socialista - antecessor do Partido Comunista (Muñoz, 1986).

Além do crescimento da classe trabalhadora, a classe média em expansão também se transformou em um fator de desestabilização do regime oligárquico, na medida em que passou a buscar uma ampliação no espaço que ocupava no Estado. Essa conjuntura, combinada com a crise econômica impulsionada pela queda do salitre depois da Primeira Guerra Mundial, enfraqueceu a oligarquia tradicional e forjou uma incipiente aliança entre a classe média emergente e os trabalhadores organizados (Benavides, 1982).

Foi através do apoio dessa aliança antioligárquica que Arturo Alessandri Palma, do Partido Liberal, elegeu-se presidente em 1920. Durante seu governo, porém, Alessandri oscilou entre atender e reprimir demandas sociais, tanto pelos empecilhos colocados pelo Congresso quanto por sua origem liberal e oligárquica (Subercaseaux, 2009) - alinhando-se mais com a classe média e com os militares do que com os trabalhadores (Faundez, 2007). O Congresso, aliás, legitimado pela estrutura parlamentarista, era um importante obstáculo à presidência, fazendo de

\footnotetext{
${ }^{3}$ Ackermann (1970) aponta que isso vai ter um impacto importante no processo de industrialização, pois, enquanto a classe trabalhadora do Brasil, por exemplo, estava em formação, facilitando a intervenção do Estado em seus interesses, a do Chile já tinha uma tradição de luta e estava organizada politicamente, impondo-se como um ator dificilmente manobrado pelo Estado e empresários. Um exemplo da precoce organização dos trabalhadores chilenos é que, entre 1890 e 1925, registrou-se uma média de nove greves por ano. Entre as mobilizações mais importantes estão a greve portuária de Valparaíso (1903), a "greve da carne" de Santiago (1905), a greve geral de Antofagasta (1906) e a “grande greve” de Tarapacá (1907) (Grez, 2000).
} 
Alessandri um grande crítico desta forma de governo. Foi somente com a dissolução do parlamentarismo que o presidente conseguiu avançar em sua agenda.

Desde sua posse, Alessandri tentou aprovar no Congresso diversas leis destinadas à regulamentação do trabalho, no entanto, os parlamentares postergavam todas as votações, concentrando-se "on their favorite pastime of bringing down cabinets" (Faúndez, 2007). A relação entre Executivo e Legislativo chegou ao limite em 1924, levando a um quadro de paralisia decisória em decorrência da resistência do Congresso em votar o orçamento. Nessa conjuntura, Alessandri solicitou aos militares, que tinham o aumento de seus salários em jogo, que mediassem a situação. Com a presença destes no parlamento, os congressistas prontamente aprovaram todas as contas do governo (Gil, 1966). Não obstante, a porta aberta por Alessandri não foi o suficiente para satisfazer as forças armadas, que, pouco tempo depois, depuseram-no.

Apesar disso, devido a cisões no comando militar, após alguns meses, Alessandri conseguiu voltar à presidência com a ajuda de um setor dos militares. É a partir dessa aliança que se estruturou a Constituição de 1925, que aboliu o parlamentarismo e fortaleceu o Executivo. Todavia, a instituição do presidencialismo não significou estabilização política, ao contrário, nos dez anos seguintes nenhum presidente concluiu seu mandato e a dissolução de ministérios permaneceu tão frequente quanto antes (Faúndez, 2007).

Além da instabilidade política, as décadas de 1920 e 1930 também foram marcadas pela crise econômica resultante tanto da derrocada do salitre, pela produção de sua versão sintética, quanto da Crise de 1929. Isso gerou a busca por um modelo econômico menos vulnerável que a exportação de commodities, dando início à estratégia de substituição de importações (Palma, 1984). Meller (1996) aponta que essa reorientação econômica não foi por motivos ideológicos, mas sim pela imposição da natureza e gravidade dos problemas econômicos gerados pela Grande Depressão, que colocaram a necessidade de diminuir a dependência ao setor externo. Contudo, a fragilidade dos governos que se seguiram e a conjuntura econômica dificultaram o estabelecimento de políticas para efetivar esse processo. Será apenas com a ascensão dos governos radicais que isso mudará, dando início ao ciclo desenvolvimentista chileno.

\section{O DESENVOLVIMENTISMO RADICAL (1938-1952)}

O Partido Radical (PR) foi criado em 1888, sendo o primeiro partido chileno a ter programa e estatuto escritos. Nestes, estabelecia como pressupostos fundamentais i) o direito de sufrágio; ii) a liberdade individual; iii) a separação da Igreja do Estado; iv) a independência do Judiciário; v) o ensino primário gratuito, laico e obrigatório, e vi) a melhora da condição legal das mulheres e dos trabalhadores. Em matéria econômica, apesar de originalmente alinhado aos ideais do liberalismo, com o início do século XX, o radicalismo passou a defender a expansão da ação estatal.

Essa reorientação ideológica foi abraçada em sua terceira Convenção Nacional, 
em 1906. A partir desse momento o partido reconhece a existência da luta de classes, ainda que recuse o marxismo como ideologia e rechace as ditaduras de qualquer tipo. Ao contrário, passa a defender um reformismo, em que o Estado atue de forma a diminuir as desigualdades sociais (Partido Radical, 1906, p. 1).

A expansão do Estado também se justificava pela necessidade de uma maior intervenção na economia. Tal visão também foi sustentada na Assembleia Radical de Santiago, em 1936, quando se destacou que as riquezas do país haviam passado às mãos do capitalismo estrangeiro, que ao desfrutar de "privilégios irritantes", estaria aniquilando e humilhando o país (Partido Radical, 1936a, p. 2).

Com essa reorientação em seu discurso, o Partido Radical tornou-se no início do século XX a terceira maior força política do país, atrás dos Liberais e dos Conservadores. Porém, a partir da década de 1920, com a crise da oligarquia, passa a conquistar mais espaço. Em uma época de eleitorado estreito e dominação da política pela oligarquia, o PR diferenciava-se por ter uma base composta por setores da classe média (Faúndez, 2007).

Foi através deste quadro que o PR formou o que Alessandri falhou em concretizar: uma genuína aliança entre a classe média e os trabalhadores. Isso foi possível, em 1936, através da criação da Frente Popular, uma aliança eleitoral que uniu os partidos Radical, Socialista, Comunista, Democrático e Radical Socialista, além da Confederación de Trabajadores de Chile (CTCH) e do Movimiento Pro-Emancipación de las Mujeres de Chile (MEMCH). Mesmo tendo existido brevemente, a Frente Popular permitiu ao partido que tomasse as rédeas da política nacional, mantendo-se no Palácio de La Moneda por três governos sucessivos.

\section{A face democrática}

A tríade de governos radicais iniciou-se com a eleição de Pedro Aguirre (1938-1941) pela já citada Frente Popular. Em um período de Frentes Populares antifascistas na Europa, o Chile foi o único país latino-americano a estabelecer um governo neste modelo. Conforme Aggio (2002), ainda que a Frente não tenha representado uma revolução política e social, ela significou uma virada profunda na história contemporânea do Chile, pois o Estado passou a agir como promotor do desenvolvimento econômico e da justiça social. O autor sublinha também que a Frente foi uma inovação no cenário latino-americano, uma vez que a modernização e a industrialização almejadas ocorreram a partir de uma coalizão de centro-esquerda e em um contexto democrático.

Apesar da dissolução da Frente em 1941, o período radical deve ser compreendido a partir da manutenção das forças que assumiram o poder, em 1938, e do relativo consenso em torno de temas como a industrialização e o papel do Estado na economia. Por todo o período, houve, então, a consciência dos atores na persecução de um projeto desenvolvimentista (Aggio, 1997). Assim, tal qual Fonseca, Cunha e Bichara (2013) caracterizaram a política econômica desenvolvimentista, a política dos governos radicais não foi errática e, mesmo com a volatilidade ineren- 
te à democracia, não cedeu às flutuações da conjuntura, mas se manteve na trajetória previamente definida.

Com a morte de Aguirre, em 1941, novas eleições foram chamadas. A escolha do candidato deu-se em uma primária disputada por Gabriel González Videla, representando o setor mais esquerdista do partido, e Juan Antonio Ríos, pela direita do partido. Por pouco mais de $1 \%$ dos votos, Ríos ganhou o direito de representar o partido nas eleições de 1942. Contudo, isso levou à perda do apoio de Socialistas e Comunistas, além de promover um racha dentro do próprio partido, que repudiou a tentativa de Ríos em se aproximar de partidos tradicionais. Durante todo o governo, o PR manteve uma postura de desconfiança ante o presidente, tendo ameaçado, por vezes, abandoná-lo devido à sua insistência em incluir os liberais no quadro ministerial (Reyes, 1989).

Apesar de tudo, Ríos logrou formar uma aliança de pequenos partidos, como o Partido Agrário, o Partido Democrático e a Falange Nacional, além de conseguir o apoio de notórias figuras liberais. Na reta final da campanha, os partidos Comunista e Socialista acabaram por manifestar seu apoio ao candidato radical, visto que seu opositor era considerado nazifascista - entretanto, não participaram do governo (Subercaseaux, 2009). Mesmo com tais contratempos, Ríos foi eleito em 1942 sob o lema "Governar é Produzir".

Já o último presidente radical, Gabriel González Videla (1946-1952), foi apoiado por uma coalizão de esquerda. No seu governo, inclusive, o Partido Comunista aceitou, pela primeira vez, fazer parte do quadro ministerial, tornando-se o primeiro partido comunista a participar de um governo no continente (Moulian, 1985). Chega a ser irônico, portanto, que em 1948, dada a conjuntura internacional da Guerra Fria, ele tenha não só rompido com os comunistas, como também tenha declarado sua ilegalidade por meio da Lei de Defesa Permanente da Democracia, conhecida popularmente como Lei Maldita. Essa virada ideológica estaria associada à barganha entre o governo chileno, junto aos Estados Unidos, por empréstimos para a criação da refinaria de petróleo de Concón, da Fundição Nacional de Paipote e da Siderúrgica de Huachipato (Collier e Sater, 2004). Rector (2005) aponta que essa ofensiva também estaria ligada ao crescimento do Partido Comunista, expresso nas eleições municipais de 1947, quando alcançou sua maior votação, cerca de $17 \%$ dos votos, e no aumento dos votos obtidos pelos partidos Socialista e Comunista entre 1937 e 1945, quando passaram de um total de 63.212 para 295.407 (Zapata, 2004). Essa medida é vista entre os radicais como o início de seu declínio e incentivou um racha em sua estrutura, dando origem ao Partido Radical Doutrinário.

Além das disputas dentro da própria coalizão governante, a oposição também foi um ator decisivo na formulação das políticas públicas. Durante todo o período, os partidos Liberal e Conservador mantiveram uma média de 50\% dos assentos no Congresso (Moulian, 1985). Isso possibilitou barganhar com a coalizão dominante, limitando e barrando políticas. O exemplo mais emblemático deu-se na criação da Corporação de Fomento da Produção (CORFO), cujo funcionamento será detalhado posteriormente. Tal medida era um dos objetivos do presidente 
Aguirre antes mesmo de sua eleição, contudo, por ser uma instituição com escopo inovador para a época, era notório que teria dificuldades de aprová-la. O terremoto de Chillán de 1939, entretanto, logo no início do mandato de Aguirre, tornou mais fácil sua aceitação pelo Congresso, já que o presidente aproveitou a situação para passar uma lei que criava ao mesmo tempo a CORFO e a Corporação de Auxílio e Reconstrução, voltada à reparação de zonas afetadas por desastres naturais (Muñoz, 1993).

Mesmo que a comoção nacional tenha ajudado a aprovação da lei, esta demandou dois meses de intensos debates no Congresso, e somente foi aprovada depois da coalização governante comprometer-se a retirar o projeto de lei que estruturava o sindicalismo rural e a não pressionar pela formação de tais sindicatos (Ortega, 1989). Deste modo, a CORFO foi aprovada pelo voto de um senador conservador e os sindicatos campesinos demoraram mais vinte e cinco anos para serem criados. Devido a essa dinâmica de acordos e pressão do Legislativo, o Executivo precisou abandonar ou adaptar pontos importantes de sua agenda, respeitando as regras do jogo democrático.

\section{A face nacional-desenvolvimentista}

A face nacional-desenvolvimentista da experiência radical expressou-se, principalmente, no esforço de industrialização, percebido como o meio de desenvolver o país e diminuir sua dependência externa. Até 1938, a industrialização baseava-se na ação privada e por tímidas políticas de fomento, sendo limitada pela orientação primário-exportadora. Então, ao posicionar o Estado como ator central neste processo, os governos radicais lhe deram um novo contorno. Para esta reorientação foi essencial a criação da Corporação de Fomento da Produção (CORFO) em 1939, responsável pela formulação de programas de desenvolvimento e pela alocação de recursos para atividades produtivas. Nesse sentido, tratou-se do primeiro órgão público com recursos para financiar atividades de investimento, constituindo-se no principal instrumento da industrialização chilena.

Em um discurso pela defesa de sua criação, Aguirre afirmou que:

O governo popular não acredita na "mão invisível" de que fala Adam Smith e confia na ação direta, preventiva, coordenadora e executora do Estado. O Estado passa a desempenhar o papel dinâmico e empreendedor que, em outros países, teve o empresário privado na promoção do crescimento econômico e que, no nosso país, não soube ou não pôde assumir. (Aguirre apud Aggio, 2002, p. 74).

De acordo com Del Pozo (1989), a CORFO dominou a vida econômica do país até 1973, criando empresas tanto estatais quanto privadas. Assim, em seus primeiros anos, durante os governos radicais, tal corporação já controlava $30 \%$ do investimento total em bens de capital, mais de $25 \%$ do investimento público e $18 \%$ do investimento bruto total (Meller, 1996). Além disso, a CORFO atuou no finan- 
ciamento do investimento industrial, cumprindo o papel de banco de desenvolvimento, nos termos de Amsden (2009).

Quanto a seu desenho institucional, sublinha-se a relativa autonomia ante a disputa partidária no Congresso, bem como o papel dirigente do Conselho administrativo, o qual era formado por 22 membros representantes da Presidência da República, do Legislativo, das empresas estatais, das associações empresariais, do Instituto de Engenheiros do Chile e da Confederação de Trabalhadores do Chile. Nesse sentido, tal estrutura caracterizava-se pela autonomia enraizada, nos termos de Evans (2004), viabilizando a negociação de metas e políticas entre governo e empresários industriais.

Foi através da CORFO que as maiores empresas estatais de setores intermediários foram criadas, como a Empresa Nacional de Eletricidade, a Companhia de Aço do Pacífico, a Empresa Nacional do Petróleo, a Indústria Açucareira Nacional, a Empresa de Manufaturas de Cobre e a Siderúrgica de Huachipato. Desse modo, a Corporação foi a base do modelo de substituição de importações chileno, tendo sua importância transcendido as fronteiras do Chile, ao servir de modelo aos outros países da América Latina, que dez anos mais tarde passaram a empregar esta política econômica (Furtado, 1970).

O empenho radical foi, por vezes, beneficiado pelo contexto internacional. Durante a Segunda Guerra Mundial, por exemplo, o aumento da demanda por cobre levou a um avanço na produção do minério, o que, sem a concorrência europeia, engendrou um salto de $50 \%$ na produção manufatureira (Collier e Sater, 2004). Aproveitando-se desse contexto, o governo Ríos criou diversas empresas estatais no setor de bens intermediários.

Com o final da guerra e com a normalização do mercado internacional, cresceu a preocupação com a volta do fluxo de produtos estrangeiros. Ante o panorama incerto, o governo criou a Comissão Nacional do Pós-Guerra, para analisar o cenário e apontar políticas a seguir - o que expandiu o já extenso rol de medidas protecionistas 4 implementadas pelos radicais (Echenique e Rodríguez, 1983).

Apesar do alinhamento com os Estados Unidos, o presidente Videla não abandonou no período pós-guerra a política industrial característica dos governos radicais. Ao contrário, enfatizou-a a partir da invocação de uma revolução industrial em 1950 (Partido Radical, 1950, p. 1).

Assim, no governo Videla, foram criadas a refinaria de petróleo de Concón, a Fundição Nacional de Paipote, a Indústria Açucareira Nacional e a Siderúrgica de Huachipato. Ademais, tal governo foi responsável pelo início da construção de seis centrais hidroelétricas e pela inauguração da Base Militar Bernardo O’Higgins e da Base Naval Arturo Prat. Ambas as bases tinham como objetivo assegurar a presença chilena na Antártida. Ainda na dimensão dos interesses estratégicos da

\footnotetext{
${ }^{4}$ Dentre as medidas empregadas, destacam-se: tarifas de importação diferenciadas; compra e venda controladas de moedas; sistema de câmbios múltiplos; câmbio especial sobrevalorizado para as exportações de cobre (Meller, 1996).
} 
defesa chilena, em 1952, a Declaração de Santiago firmou a Zona Econômica Exclusiva, estabelecendo a soberania nacional sobre uma faixa de 200 milhas marítimas da costa do país.

Em termos concretos, segundo Olmos e Silva (2010), no período radical a indústria cresceu uma média de $7,5 \%$ ao ano, aumentando sua participação no PIB de $7,9 \%$ em 1929 para $23 \%$ em 1955 . O emprego industrial, por sua vez, cresceu cerca de $20 \%$ (Rector, 2005). Além disso, o protagonismo estatal na industrialização engendrou a formação de uma nova burguesia, originada a partir de segmentos da classe média urbana, portadora de uma mentalidade antioligárquica e simpática à intervenção estatal na economia 5 .

\section{A face social}

A face social dos governos radicais caracterizou-se pela maior resistência por parte da oposição, compondo, portanto, a maioria dos programas barrados pelo Congresso (Konings, 2010). Ainda assim, alguns avanços foram alcançados. Por exemplo, durante o governo Aguirre, apostou-se na expansão da abrangência de políticas já vigentes, fazendo com que o número de trabalhadores incluídos na previdência social saltasse de $52 \%$ para $80 \%$ durante seu governo (Faúndez, 2007).

Além disso, consolidou-se a oferta de uma educação pública, laica e obrigatória. Dessa forma, foram criadas 500 escolas, sextuplicando o número de alunos matriculados no ensino primário (Quezada, 2011), bem como se expandiram as escolas técnicas, voltadas à educação para indústria. Tal política foi mantida ao longo dos governos radicais, culminando com a fundação da Universidade Técnica do Estado em 1947.

Institucionalizou-se também o salário mínimo e uma política de aumento salarial conhecida como "política do sacrifício compartilhado", que determinou o custeio do aumento dos salários pelo lucro da empresa. Em 1941, ainda foi estabelecido o aumento salarial automático, indexando-o ao avanço do custo de vida (Chile, 1955). Vale notar que, durante os governos radicais, o salário mínimo sempre se manteve acima da inflação, sendo o crescimento do salário real uma média de 3,5\% ao ano (Dingemans, 2011). A política de aumento salarial foi, então, um dos eixos centrais do período radical, conformando um modelo de crescimento liderado pelos salários (wage-led growth). Conforme Ackermann (1970), em diversas vezes, tal política sobrepujou até mesmo a política industrial e o controle da inflação ${ }^{6}$ na ordem de prioridade dos governos do período.

\footnotetext{
${ }^{5}$ Em seu estudo sobre o empresariado chileno, Ackermann (1970) percebe que a burguesia formada nos anos radicais provinha de setores médios, técnicos e profissionais, ao contrário do que aconteceu no resto da América Latina e no próprio Chile na industrialização da década de 1920, quando pequena parcela da oligarquia se industrializou. Conforme a autora, essa nova burguesia não só era a favor da intervenção do Estado na economia, como $70 \%$ dela achava que o desenvolvimento da indústria privada não era possível sem o envolvimento estatal.

${ }^{6}$ Conforme Lessa (1967), a ideia de que a inflação era o preço de um progresso rápido era amplamente
} 
As diversas leis trabalhistas implementadas, combinadas com a presença dos socialistas e comunistas no governo, geraram um clima institucional e político propício ao crescimento da afiliação sindical, que, entre 1929 e 1953, passou de 50 mil afiliados a 300 mil (FLORES, 2003). Não obstante, é preciso reconhecer que a consolidação do poder sindical aprofundou os conflitos trabalhistas, e o aumento do salário superior ao aumento da produtividade pode ter afetado negativamente a trajetória da taxa de lucro, a rentabilidade e o investimento na indústria (Meller, 1996). Nesse sentido, há risco de que o regime de crescimento adotado pelos governos radicais tenha gestado um cenário de profit-squeeze, o qual ajudaria a explicar o afastamento da burguesia em relação à concertação social, culminando com a escalada dos conflitos políticos e o golpe militar de 1973.

\section{CONSIDERAÇÕES FINAIS}

A experiência radical chilena, coerente com o paradigma desenvolvimentista, caracterizou-se pela manutenção concomitante e harmônica das faces nacional, democrática e social do desenvolvimentismo radical. Em relação à primeira face, os governos radicais concentraram-se na criação de diversas empresas estatais, bem como na formulação de medidas voltadas à defesa nacional. Isso significou a conquista de autonomia em áreas estratégias no que tange tanto a setores econômicos quanto ao próprio território chileno.

Quanto à face democrática, apesar de engessar algumas iniciativas presidenciais, esta permitiu a formação de um clima de relativo consenso em torno do papel do Estado na economia - consenso que configurou o primeiro degrau rumo às presidências de Eduardo Frei Montalva e Salvador Allende. Assim, a despeito das divergências entre os partidos da base dos governos radicais e da oposição do Congresso, o Partido Radical garantiu certa estabilidade ao sistema político e, pelo menos até a Lei Maldita, não o fez a partir da vedação à livre manifestação e organização dos diversos segmentos sociais.

Já no que tange ao conteúdo social do desenvolvimentismo radical, este decorreu tanto das inclinações ideológicas do partido quanto da sua política de alianças, principalmente, junto a socialistas e comunistas. Também é importante ressaltar que a independência sindical ante o governo gestou um ator político a ser disputado eleitoralmente e, portanto, considerado no desenvolvimento de políticas. Isso tudo fez com que políticas como o avanço do salário mínimo se tornassem centrais para os governos, melhorando a distribuição de renda no país.

Portanto, durante os governos radicais, a ação estatal logrou transformar a estrutura econômica e social chilena. Em um período de ebulição política no mun-

defendida nos governos radicais, evitando a tomada de medidas anti-inflacionárias por medo de interromper o desenvolvimento econômico. Assim, a inflação se manteve ascendente durante todo o período. Se em meados da década de 1930 ela alcançava a marca dos 7\%, em 1946 o índice foi a 15\% e em 1951 atingiu os $21 \%$ (RECTOR, 2005). 
do, este processo prescindiu de uma estratégia revolucionária ou mesmo de medidas autoritárias. Dessa maneira, o estudo aprofundado das diversas faces do desenvolvimentismo radical é uma agenda promissora de pesquisa, afinal, a análise da implementação de políticas desenvolvimentistas em um contexto democrático pode contribuir para a compreensão dos desafios de governos contemporâneos que reivindicam a herança desenvolvimentista, principalmente, na América do Sul.

Em um Brasil no qual o embate entre desenvolvimentismo e neoliberalismo ainda permeia o debate econômico, revisitar os erros e acertos da experiência radical chilena traz mais informações do que outros exemplos mais referidos na literatura, tais como a Era Vargas (1930-1945) e a Ditadura Civil-Militar (1964-1985), nos quais a institucionalidade autoritária demoveu obstáculos a implementações de medidas econômicas estratégicas. Além disso, um desenvolvimentismo sem democracia corre o risco de aprofundar a desigualdade social e a pobreza, bases fundamentais do atraso econômico que procura superar.

\section{REFEREÊNCIAS BIBLIOGRÁFICAS}

Ackermann, María Gracia. (1970) Burguesía industrial e ideología de desarrollo en Chile. Santiago: FLACSO.

Aggio, Alberto. (2002) Democracia e socialismo: a experiência chilena. São Paulo: Annablume.

Aggio. Alberto. (1997) "Frente popular, modernização e revolução passiva no Chile”, Revista Brasileira de História, 17(34): 221-244.

Amsden, Alice. (2009) A ascensão do "resto”. São Paulo: UNESP.

Arrizabalo, Xabier. (1997) Crisis y ajuste en la economía mundial. Implicaciones y significado de las políticas del FMI-BM. Madrid: Ed. Síntesis.

Bastos, Pedro Paulo Zahluth. (2012) "A economia política do novo-desenvolvimentismo e do social desenvolvimentismo", Economia e Sociedade, 21(especial): 779-810.

Benavides, Leopoldo. (1982) La Democratizacion y el Desarrollo en el Proyecto Popular: Chile 18901970. Santiago: FLACSO.

Bhaduri, Amid; Marglin, Stephen. (1990) "Unemployment and the real wage: the economic basis for contesting political ideologies", Cambridge Journal of Economics, 14(4): 375-393.

Bresser-Pereira, Luiz Carlos. (2012) “A taxa de câmbio no centro da teoria do desenvolvimento”, Estudos Avançados, 26(75): 7-28.

Bresser-Pereira, Luiz Carlos; Gala, Paulo. (2010) “Macroeconomia estruturalista do desenvolvimento", Revista de Economia Política, 30(4): 663-686.

Cardoso, Fernando Henrique. (1971) Política de desenvolvimento em sociedades dependentes: ideologias do empresariado industrial argentino e brasileiro. Rio de Janeiro: Zahar.

Cardoso, Fernando Henrique; Faletto, Enzo. (1970) Dependência e desenvolvimento na América Latina: ensaio de interpretação sociológica. Rio de Janeiro: Zahar Editores.

Carneiro. Ricardo de Medeiros. (2012) "Velhos e novos desenvolvimentismos", Economia e Sociedade, 21(especial): 779-810.

Chile. (1956) Exposición del Directorio del Banco Central de Chile relacionada con la situación económica y financiera del país, Memoria Anual del Banco Central de Chile 1955. Santiago: BCC.

Collier, Simon; Sater, William F. (2004) A History of Chile, 1808-2002. Cambridge: Cambridge University Press.

Cruz, Aníbal Pinto. (1973) Chile: un caso de desarrollo frustrado. Santiago: Editorial Universitaria.

Del Pozo, José. (1989) “Los gobiernos radicales en Chile frente al desarrollo (1938-1952)”, Caravelle, 53(01): 37-64. 
Dingemans, Alfonso. (2011) Una historia económica sin fin. Chile y Argentina en la formación de una economía de mercado, 1973-2001. Santiago: RIL editores.

Echenique, Antonia; Rodríguez; Concepción. (1983) Historia de la Compañía de Acero del Pacífico S.A.:1905-1950. Santiago: CAP.

Evans, Peter. (2004) Autonomia e parceria: Estados e transformação industrial. Rio de Janeiro: Editora UFRJ.

Faúndez, Julio. (2007) Democratization, Development and Legality: Chile 1831-1973. New York: Palgrave Macmillan.

Ferrari Filho, Fernando; Fonseca, Pedro. (2015) "Which developmentalism? A Keynesian-Institutionalist proposal”, Review of Keynesian Economics, 3(1): 90-107.

Ferrari Filho, Fernando; Paula, Luiz Fernando. (2016) "Padrões de crescimento e desenvolvimentismo: uma perspectiva keynesiano-institucionalista”, Nova Economia, 26(3): 775-809.

Flores, Juan Carlos. (2003) Las politicas laborales en Chile 1900-1970. Documento de trabalho.

Fonseca, Pedro. (2014) "Desenvolvimentismo: a construção do conceito". In: Calixtre, A; Biancarelli, A; Cintra, M. A. M. (Orgs.). Presente e Futuro do desenvolvimento brasileiro. Brasília: Ipea.

Fonseca, Pedro. (2003) "Sobre a intencionalidade da política industrializante do Brasil na década de 1930”, Revista de Economia Política, 23(1): 133-148.

Fonseca, Pedro; Cunha, André; Bichara, Julimar. (2013) “O Brasil na Era Lula: Retorno ao Desenvolvimentismo?", Nova Economia, 23(2): 403-428.

Furtado, Celso. (1984) Cultura e desenvolvimento em época de crise. São Paulo: Paz e Terra.

Furtado, Celso. (1970) La economía latinoamericana: una síntesis desde la conquista ibérica hasta la revolución cubana. Santiago: Universitaria.

Furtado, Celso. (1977) Prefácio a Nova Economia Política. Rio de Janeiro: Paz e Terra.

Garretón, Manuel Antonio. (2007) "Matriz sociopolitica y desarrollo socio-economico en Chile". IPPG Programme Office, IDPM, School of Environment \& Development Discussion Paper Series n. $15 \mathrm{~A}$.

Gil, Federico. (1966) The Political System of Chile. University of New Mexico. Boston: Houghton Mifflin.

Grez, Sergio. (2000) "Transición en las formas de lucha: motines peonales y huelgas obreras en Chile (1891-1907)". Historia, 33: 141-225.

Hein, E. (2013) “Wage- and profit-led regimes”. In: King, J. (ed.). The Elgar Companion to Post-Keynesian Economics. Cheltenham: Edward Elgar.

Herrlein JR., Ronaldo. (2014) A construção de um Estado democrático para o desenvolvimento no século XXI. In: Texto para discussão/Instituto de Pesquisa Econômica Aplicada. Rio de Janeiro: IPEA.

Kalecki, Michal. (1987) Crescimento e ciclo das economias capitalistas. São Paulo: Hucitec.

Keynes, John. (1996) Teoria geral do emprego, do juro e da moeda. São Paulo: Nova Cultural.

Lessa, Carlos. (1967) "DAs experiências de política econômica: Brasil-Chile”. El Trimestre Econômico, 34(135): 445-487.

Meller, Patricio. (1996) Un siglo de economía política chilena (1890-1990). Santiago: Andrés Bello.

Monteón, Michael. (1982) Chile in the Nitrate Era. Madison: University of Wisconsin Press.

Morris, James. (2000) "Las élites, los intelectuales y el consenso”. In: Godoy, Hernán. Estructura social de Chile. Santiago: Editorial Los Andes.

Moulian, Tomás. (1985) "Violencia, gradualismo y reformas en el desarrollo político chileno". In: Adulnate, A.; Flisfisch, A.; Moulian, T. (Orgs.). Estudios sobre el sistema de partidos en Chile. Santiago: Flacso.

Muñoz, Oscar (ed.). (1993) Historias personales, políticas públicas. Santiago: Editorial los Andes.

Olmos, Claudio; Silva, Rodrigo. (2010) "El rol del estado chileno en el desarrollo de las políticas de bienestar", Némesis, 8: 89-102.

Oreiro, José Luis; Paula, Luiz Fernando. (2007) "Strategy for economic growth in Brazil: a Post-Keynesian approach”. In: Arestis, P.; Baddeley, M; Mccombie, J.S.L (eds). Economic Growth: new directions in theory and policy. Edward Elgar: Alderhot. 
Oreiro, José Luis; Paula, Luiz Fernando. (2012) “O novo-desenvolvimentismo e a agenda de reformas macroeconômicas para o crescimento sustentado com estabilidade de preços e equidade social". In: Oreiro, J.L.; Paula, L.F.; Basilio, F. (Ed.). Macroeconomia do Desenvolvimento: Ensaios sobre restrição externa, financiamento e política macroeconômica. Recife: Editora da UFPE.

Ortega, Luis. (1989) Corporación de Fomento de la Producción: 50 años de realizaciones 1939-1989. Santiago: Universidad de Santiago de Chile.

Palma, Gabriel. (1984) “Chile 1914-1935: De economía exportadora a sustitutiva de importaciones”, Colección de Estudios del CIEPLAN, 12: 61-88.

Partido Radical. (1906) Convenção do Partido Radical.

Partido Radical. (1936a) Assembleia Radical de Santiago.

Partido Radical. (1950) Discurso de inauguração da Siderúrgica de Huachipato.

Przeworski, Adam. (1989) Capitalismo e social-democracia. São Paulo: Companhia das Letras.

Rector, John. (2003) The History of Chile. New York: Palgrave Macmillan.

Reyes, Jaime. (1989) “El Presidente y su partido durante la época radical. Chile 1938-1952”, Estudios Públicos, 35: 71-101.

Rossi, Pedro. (2015) Regime macroeconômico e o projeto social-desenvolvimentista. In: Texto para discussão/Instituto de Pesquisa Econômica Aplicada. Rio de Janeiro: IPEA.

Sen, Amartya. (1999) Desenvolvimento como Liberdade. São Paulo: Companhia das Letras.

Subercaseaux, Bernardo. (2009) "Imaginario político de transformación”, Universum, 24(2): 218-260.

Unger, Roberto Mangabeira. (2008) O que a esquerda deve propor. Rio de Janeiro: Civilização Brasileira.

Van Der Laan, Cesar Rodrigues; Cunha, André Moreira; Fonseca, Pedro Cezar Dutra. (2012) “Os pilares institucionais da política cambial e a industrialização nos anos 1930", Revista de Economia Politica, 32(4): 597-614.

Vial, Gonzalo. (1981) Historia de Chile (1891 - 1973). La sociedad chilena en el cambio de siglo (1891-1920). Volume I. Tomo 2. Santiago: Editorial Santillana.

Wade, Robert. (1999) El mercado dirigido: la teoría económica e la function del gobierno en la industrialización del Este de Asia. México: Fondo de Cultura Económica.

Zapata, Francisco. (2004) "De la democracia representativa a la democracia Movimiento obrero y sistema político en Chile”, Revista Enfoques, 2(3): 125-155. 